\title{
Active Thrust on an Inclined Retaining Wall with Inclined Cohesionless Backfill due to Surcharge Effect
}

\author{
D. M. Dewaikar, S. R. Pandey, and Jagabandhu Dixit \\ Department of Civil Engineering, Indian Institute of Technology Bombay, Mumbai 400076, India \\ Correspondence should be addressed to Jagabandhu Dixit, jagabandhu@iitb.ac.in
}

Received 13 March 2012; Accepted 8 May 2012

Academic Editor: A. P. Schwab

Copyright ( $) 2012$ D. M. Dewaikar et al. This is an open access article distributed under the Creative Commons Attribution License, which permits unrestricted use, distribution, and reproduction in any medium, provided the original work is properly cited.

\begin{abstract}
A method based on the application of Kötter's equation is proposed for the complete analysis of active thrust on an inclined wall with inclined cohesionless backfill under surcharge effect. Coulomb's failure mechanism is considered in the analysis. The point of application of active thrust is determined from the condition of moment equilibrium. The coefficient of active pressure and the point of application of the active thrust are computed and presented in nondimensional form. One distinguishing feature of the proposed method is its ability to determine the point of application of active thrust on the retaining wall. A fairly good comparison is obtained with the existing solutions.
\end{abstract}

\section{Introduction}

Active earth pressure evaluation is required for the design of geotechnical structures such as retaining walls, sheet piles, basements, and tunnels. Active thrust acting on a retaining wall is dependent of many parameters. The theories proposed by Coulomb [1] and Rankine [2] remain the fundamental approaches to analyze the active earth pressures. Coulomb [1] studied the earth pressure problems using the limit equilibrium method considering a triangular wedge of backfill behind a rough retaining wall with a plane failure surface and this theory is well verified for the frictional soil in active state. The point of application of active thrust is assumed at a distance one-third of the height of the wall from its base and independent of different parameters such as soil friction angle, $\phi$, angle of wall friction, $\delta$, backfill angle, $\beta$, and wall inclination angle. Coulomb's [1] approach does not use moment equilibrium equation for the analysis, since the distribution and point of application of reaction on the failure plane are unknown. If the distribution and point of application of soil reaction on the failure plane are known, then the point of application of active thrust can be determined using moment equilibrium equation. The limit equilibrium method assuming appropriate failure surface is most frequently used to analyze static earth pressure.
A failure mechanism was proposed by Terzaghi [3] that assumes a log-spiral failure surface originating from the base of the wall, followed by a tangent, that meets the ground surface at an angle corresponding to Rankine's [2] active earth pressure. Several experimental, analytical, and numerical studies were performed to evaluate the earth pressures on the retaining walls [4-14]. Some rigorous approaches such as finite element methods were attempted to determine the distribution of earth pressures on the retaining wall. Others prepared the tables for the calculation earth pressures based on log-spiral failure surface [15]. Active earth pressure coefficients for cohesionless soil were also computed using the method of slices by considering the soil mass in the state of limit equilibrium $[16,17]$. The charts were prepared for the calculation earth pressures based on log-spiral failure surface [18]. Discrete element analysis is used to evaluate active and passive pressure distributions on the retaining wall [19].

Recently the active earth pressure coefficients were computed based on the lower bound theorem of plasticity [20]. Upper-bound theorem of limit analysis was used to evaluate earth pressure coefficients due to soil weight, vertical surcharge loading, and soil cohesion for the case of an inclined wall and sloping cohesionless backfill [21]. Kötter's [22] equation was suitably used to determine the point of application of active thrust by taking moments of all the forces and 


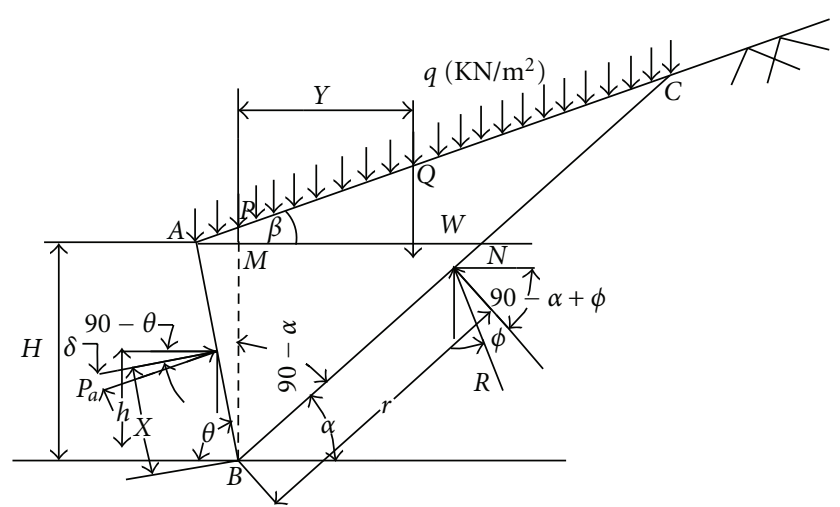

FIGURE 1: Free body diagram of the trial failure wedge $A B C$.

reaction about the base of the retaining wall [23]. A method was proposed by Kame et al. [24] to determine the active earth pressure and its point of application on a vertical wall retaining horizontal cohesionless backfill based on log-spiral failure mechanism coupled with Kötter's equation. Dewaikar et al. [25] used Kötter's equation to evaluate the magnitude of active thrust on an inclined wall retaining horizontal cohesionless backfill with uniform surcharge and to find out the point of application of reaction on the failure surface.

The objective of this study is to present a mathematical approach with a high degree of simplicity for the evaluation of the active thrust and its point of application. The analysis considers the free body diagram of the retaining wall in a very simple and analytical procedure and is easier for engineering application. The validity of the proposed approach is checked with previous available results.

\section{Analysis of Active Thrust}

The active thrust, $P_{a}$, is determined from the conditions of force equilibrium and its point of application is determined from the conditions of moment equilibrium. Figure 1 shows an inclined retaining wall, with inclined cohesionless backfill subjected to a uniform surcharge intensity of $q \mathrm{KN} / \mathrm{m}^{2}$. A trial plane failure surface [1] is considered which meets the ground surface at an angle, $\alpha$ with the horizontal. The trial wedge $A B C$ is in equilibrium under the effect of three different forces: (1) the equivalent force of the surcharge, $W$ (2) the soil reaction, $R$ along the face trial failure $B C$, at an angle $\phi$ to the normal on $B C$ and (3) the active thrust $P_{a}$, at an angle $\delta$ to the normal on the back.

The symbols used in Figure 1 are defined as follows.

$P_{a}$ : active thrust.

$W$ : equivalent force of the surcharge.

$R$ : soil reaction on the failure wedge.

$H$ : height of the retaining wall.

$h$ : height of point of application of active thrust from the wall base.

$\theta$ : inclination of the retaining wall with the horizontal. $\delta$ : friction angle between the wall and soil backfill. $\phi$ : soil friction angle.

$\alpha$ : inclination of the trial failure plane with the horizontal.

$q$ : intensity of surcharge in $\mathrm{kN} / \mathrm{m}^{2}$.

Equating all the forces in the vertical and horizontal direction, the following force equilibrium conditions are obtained.

Horizontal force equilibrium:

$$
P_{a} \sin (\theta-\delta)=R \sin (\alpha-\phi)
$$

from which $R$ is obtained as

$$
R=\frac{P_{a} \sin (\theta-\delta)}{\sin (\alpha-\phi)}
$$

Vertical force equilibrium:

$$
P_{a} \cos (\theta-\delta)+R \cos (\alpha-\phi)=A C \cdot q
$$

substituting the value of $R$ from (2) into (3)

$$
\begin{gathered}
P_{a} \cos (\theta-\delta)+\frac{P_{a} \sin (\theta-\delta)}{\sin (\alpha-\phi)} \cos (\alpha-\phi)=A C \cdot q \\
P_{a} \cos (\theta-\delta)+P_{a} \sin (\theta-\delta) \cot (\alpha-\phi)=A C \cdot q .
\end{gathered}
$$

From (5), $P_{a}$ is obtained as

$$
P_{a}=\frac{A C \cdot q}{\cos (\theta-\delta)+[\sin (\theta-\delta) \cot (\alpha-\phi)]} .
$$

Now, applying sine rule to the triangle $C A N$,

$$
\frac{A C}{\sin (180-\alpha)}=\frac{A N}{\sin (\alpha-\beta)}
$$

or

$$
A C=\frac{A N \cdot \sin (180-\alpha)}{\sin (\alpha-\beta)} .
$$

Referring to Figure 1,

$$
A N=H(\cot \theta+\cot \alpha) .
$$

Substituting the value of $A N$ in (8), $A C$ is obtained as,

$$
A C=\frac{H(\cot \alpha+\cot \theta) \sin \alpha}{\sin (\alpha-\beta)} .
$$

Substituting the value of $A C$ in (6), the magnitude of active thrust $P_{a}$ is expressed as

$$
P_{a}=\frac{q H(\cot \alpha+\cot \theta) \sin \alpha}{\sin (\alpha-\beta)[\cos (\theta-\delta)+\sin (\theta-\delta) \cot (\alpha-\phi)]} .
$$

The maximum value of active thrust $\left(P_{a}\right)$ is obtained when the inclination of the failure plane, $B C$, with the horizontal reaches the critical value, $\alpha_{\mathrm{cr}}$. 


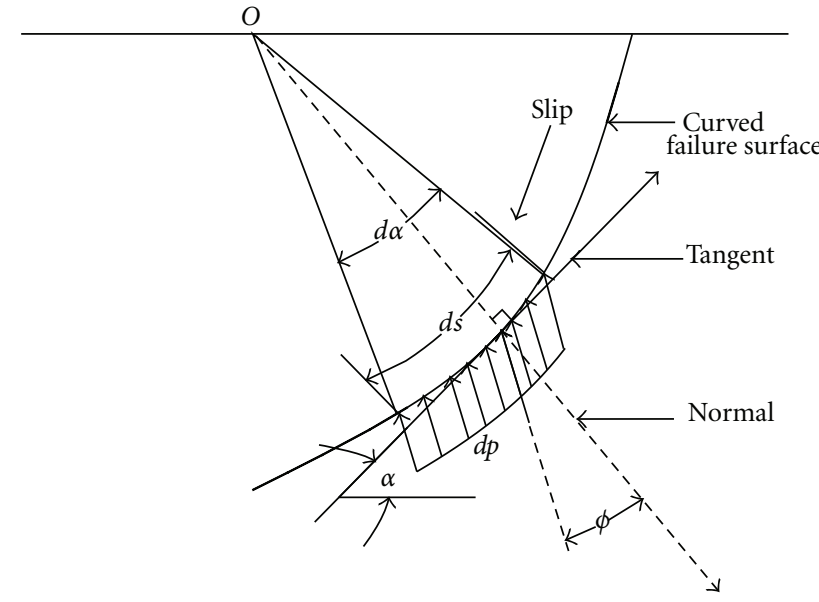

FIgURE 2: Reactive pressure distribution along the failure surface.

\section{Evaluation of Soil Reaction on the Failure Surface}

In a cohesionless soil medium with active state of equilibrium under plane strain condition, Kötter's [22] equation is given as (Figure 2)

$$
\frac{d p}{d s}-2 p \tan \phi \frac{d \alpha}{d s}=\gamma \sin (\alpha-\phi) s
$$

where

$d p$ : differential reactive pressure at a point on the failure surface,

$d s$ : elemental length of the failure surface,

$\alpha$ : angle made by the tangent at the point of interest with the horizontal,

$\phi$ : soil friction angle and,

$\gamma$ : soil unit weight.

In the present analysis, only surcharge effect is taken into consideration, and therefore $\gamma$ becomes zero. With this consideration (12) can be written as

$$
\frac{d p}{d \alpha}=2 p \tan \phi
$$

or

$$
d p=2 p \tan \phi d \alpha
$$

For a plane failure surface, $d \alpha$ is zero and the corresponding solution for the reactive pressure, $p$, is obtained as

$$
p=\text { constant }
$$

The above solution indicates that soil reactive pressure $(p)$ is uniformly distributed along the failure plane, $B C$. Therefore, the resultant soil reaction, $R$, acts at the mid-point of the failure plane, $B C$. The magnitude of soil reaction is computed after knowing the critical value, $\alpha_{\mathrm{cr}}$, of the angle,

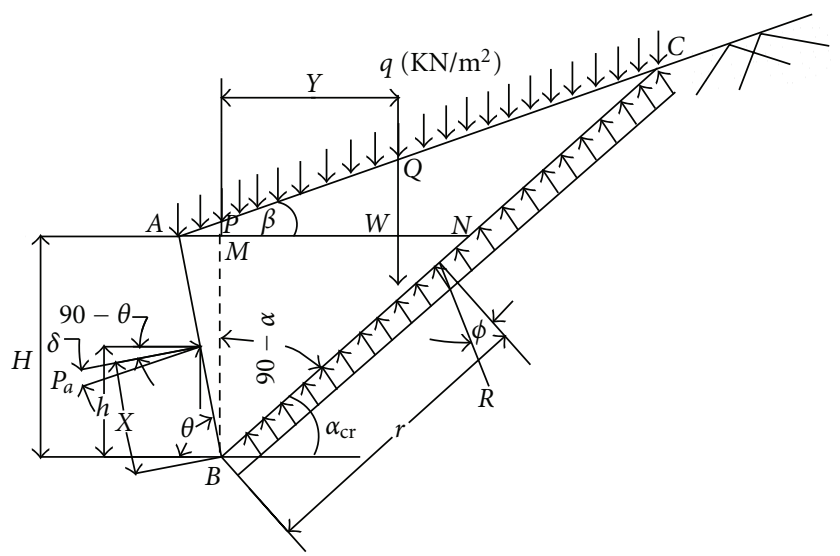

Figure 3: Free body diagram of the failure wedge $A B C$.

$\alpha$. Substituting the value of $P_{a}$ from (11) in to (2), the soil reaction $R$ on the failure surface is obtained as

$$
\begin{aligned}
R= & \frac{q H\left(\cot \alpha_{\mathrm{cr}}+\cot \theta\right) \sin (\theta-\delta) \sin \alpha_{\mathrm{cr}}}{\sin \left(\alpha_{\mathrm{cr}}-\phi\right) \sin \left(\alpha_{c r}-\beta\right)} \\
& \times \frac{1}{\left[\cos (\theta-\delta)+\sin (\theta-\delta) \cot \left(\alpha_{\mathrm{cr}}-\phi\right)\right]}
\end{aligned}
$$

\section{Point of Application of the Active Thrust}

After obtaining the value of $P_{a}$, the condition of moment equilibrium is applied. Figure 3 shows the free body diagram of the failure wedge $A B C$. The equivalent force of surcharge on the trial wedge, $A B C$, is $A C \cdot q$, which acts at the midpoint of $A C$, that is, at a distance $Y$ from the vertical line passing through the base the wall. As the distribution of reaction $(R)$ is uniform along the failure surface, it acts at the mid-point of the failure plane $B C$. The moments of all forces and reactions are taken about the base of the wall, at point $B$.

Moment equilibrium condition:

$$
P_{a} \cos \delta \cdot X+q A C \cdot Y=R \cos \phi \frac{B C}{2} .
$$

The surcharge acts at the center of $A C$ with the distance $Y$ given as,

$$
Y=P Q \cos \beta,
$$

where

$$
P Q=\frac{A C}{2}-A P
$$

From triangle AMP,

$$
A P=\frac{H \cot \theta}{\cos \beta} .
$$

Now, substituting the value of $A C$ from (10) and AP from (20) in (19) (Figure 3), $P Q$ is obtained as

$$
P Q=\frac{H\left(\cot \theta+\cot \alpha_{\mathrm{cr}}\right) \sin \alpha_{\mathrm{cr}}}{2 \sin \left(\alpha_{\mathrm{cr}}-\beta\right)}-\frac{H \cot \theta}{\cos \beta} .
$$


TABLE 1: Variation of the height of point of application of active thrust, $H_{r}$, with angle of wall back $(\theta)$, angle of soil friction $(\phi)$, soil and wall friction $(\delta)$ and backfill slope $(\beta)$.

\begin{tabular}{|c|c|c|c|c|}
\hline $\begin{array}{l}\text { Angle of wall back, } \theta \\
\text { (degrees) }\end{array}$ & $\begin{array}{l}\text { Angle of soil friction, } \phi \\
\text { (degrees) }\end{array}$ & $\begin{array}{l}\text { Angle of wall friction, } \delta \text { (degrees) } \\
\qquad(\delta=2 / 3 \phi)\end{array}$ & $\begin{array}{c}\text { Angle of backfill slope, } \beta \\
\text { (degrees) } \beta / \phi=(0.4,0.6,0.8)\end{array}$ & $H_{r}(=h / H)$ \\
\hline \multirow{12}{*}{80} & \multirow{3}{*}{40} & \multirow{3}{*}{26.667} & 16 & 0.336 \\
\hline & & & 24 & 0.397 \\
\hline & & & 32 & 0.511 \\
\hline & \multirow{3}{*}{35} & \multirow{3}{*}{23.333} & 14 & 0.388 \\
\hline & & & 21 & 0.451 \\
\hline & & & 28 & 0.566 \\
\hline & \multirow{3}{*}{30} & \multirow{3}{*}{20} & 12 & 0.446 \\
\hline & & & 18 & 0.510 \\
\hline & & & 24 & 0.622 \\
\hline & \multirow{3}{*}{25} & \multirow{3}{*}{16.667} & 10 & 0.512 \\
\hline & & & 15 & 0.575 \\
\hline & & & 20 & 0.682 \\
\hline \multirow{12}{*}{70} & \multirow{3}{*}{40} & \multirow{3}{*}{26.667} & 16 & 0.657 \\
\hline & & & 24 & 0.708 \\
\hline & & & 32 & 0.814 \\
\hline & \multirow{3}{*}{35} & \multirow{3}{*}{23.333} & 14 & 0.625 \\
\hline & & & 21 & 0.68 \\
\hline & & & 28 & 0.775 \\
\hline & \multirow{3}{*}{30} & \multirow{3}{*}{20} & 12 & 0.605 \\
\hline & & & 18 & 0.648 \\
\hline & & & 24 & 0.729 \\
\hline & \multirow{3}{*}{25} & \multirow{3}{*}{16.667} & 10 & 0.584 \\
\hline & & & 15 & 0.625 \\
\hline & & & 20 & 0.692 \\
\hline
\end{tabular}

Substituting the value of $P Q$ from (21) into (18), the point of application of equivalent surcharge force from the axis BM (Figure 3 ) is computed as

$$
Y=\cos \beta\left[\frac{H\left(\cot \theta+\cot \alpha_{\mathrm{cr}}\right) \sin \alpha_{\mathrm{cr}}}{2 \sin \left(\alpha_{\mathrm{cr}}-\beta\right)}-\frac{H \cot \theta}{\cos \beta}\right] .
$$

The soil reaction $R$ acts at the midpoint of the failure plane $B C$, with the distance, $r$ (Figure 3 ), computed as

$$
r=\frac{B C}{2} \text {. }
$$

Referring to Figure 3, $B C$ is obtained as

$$
B C=\frac{H \sin (\theta+\beta)}{\sin \left(\alpha_{\mathrm{cr}}-\beta\right) \sin \theta} .
$$

Substituting the value of $B C$ from (24) and $Y$ from (22) into (17), the distance $X$ is obtained:

$$
\begin{aligned}
P_{a} \cos \delta & \cdot X+q \cdot A C \cos \beta \\
& \times\left[\frac{H\left(\cot \theta+\cot \alpha_{\mathrm{cr}}\right) \sin \alpha_{\mathrm{cr}}}{2 \sin \left(\alpha_{\mathrm{cr}}-\beta\right)}-\frac{H \cot \theta}{\cos \beta}\right] \\
= & R \cos \phi \frac{H \sin (\theta+\beta)}{2 \sin \left(\alpha_{\mathrm{cr}}-\beta\right) \sin \theta}
\end{aligned}
$$

\section{Results and Discussions}

One of the aims of the proposed analysis is the determination of point of application of the active thrust in a nondimensional form with the consideration of effect of 


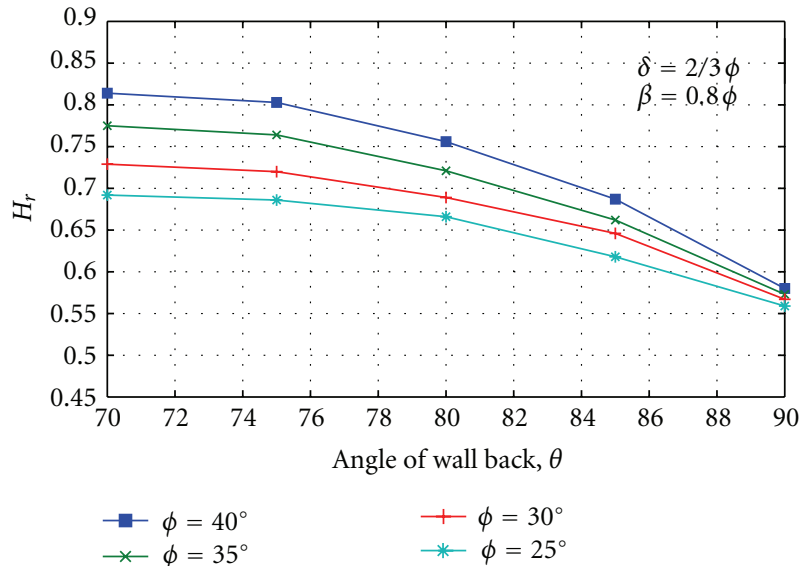

FIgURE 4: Variation of $H_{r}$ with angle of wall back, $\theta$, for $\beta=0.8 \phi$.

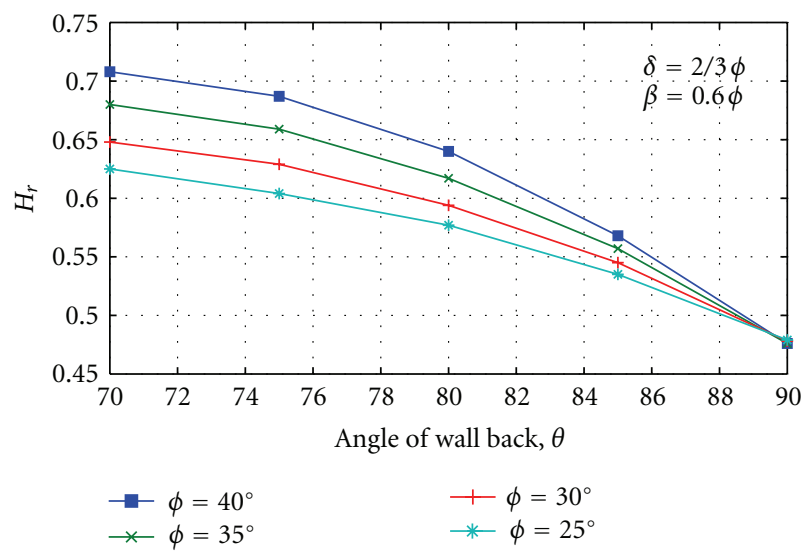

Figure 5: Variation of $H_{r}$ with angle of wall back, $\theta$, for $\beta=0.6 \phi$.

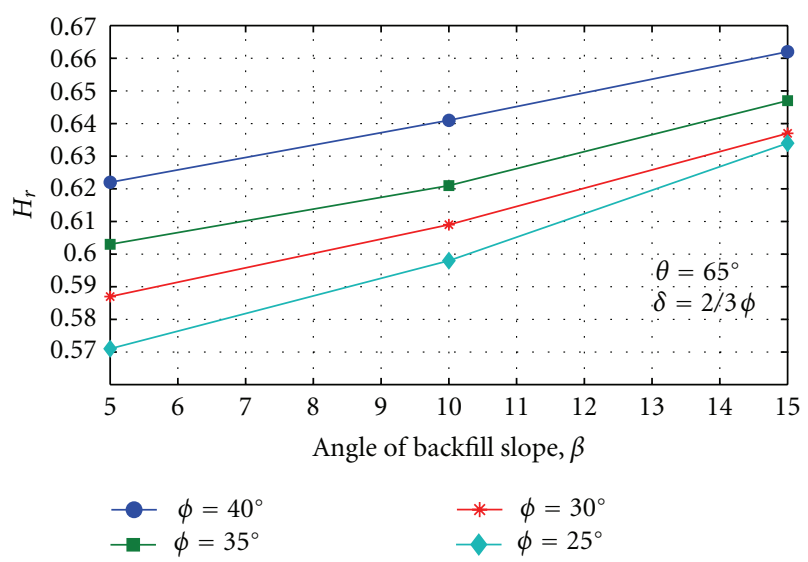

FIGURE 6: Variation of $H_{r}$ with angle of backfill slope, $\beta$, for $\theta=65^{\circ}$.

various parameters. The height, $h$, of point of application of the active thrust due to surcharge effect is expressed in a nondimensional form, $H_{r}$, expressed as $h / H$. The results are reported as shown in Table 1 along with figures that are described below.

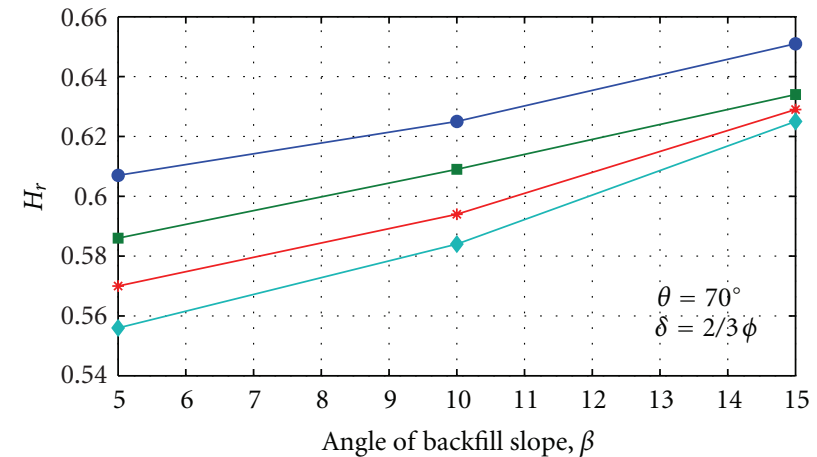

$$
\begin{array}{ll}
\multimap \phi=40^{\circ} & \rightarrow \phi=30^{\circ} \\
\multimap \phi=35^{\circ} & \multimap \phi=25^{\circ}
\end{array}
$$

Figure 7: Variation of $H_{r}$ with angle of backfill slope, $\beta$, for $\theta=70^{\circ}$.

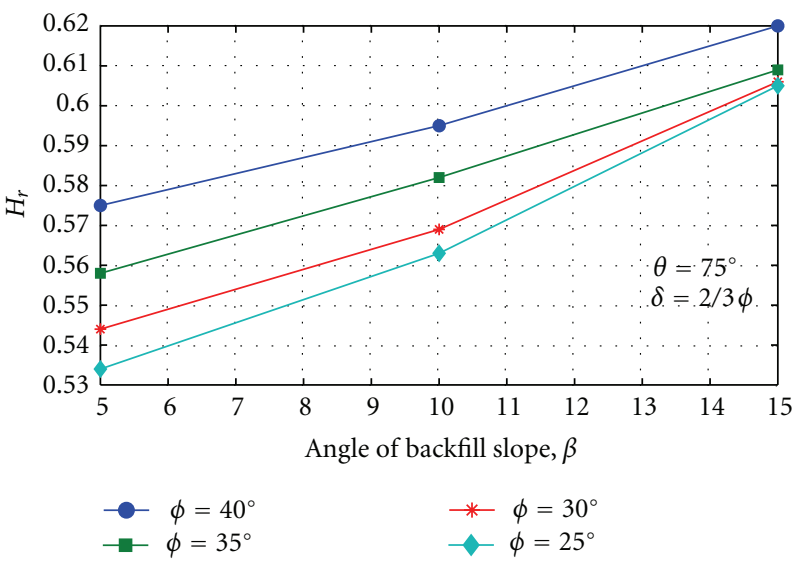

Figure 8: Variation of $H_{r}$ with angle of backfill slope, $\beta$, for $\theta=75^{\circ}$.

In Figures 4 and 5, variation of $H_{r}$ with the angle of wall back, $\theta$, is shown for $\delta=2 / 3 \phi$ and $\beta=0.8 \phi$ and $0.6 \phi$ respectively. It is seen that $H_{r}$, decreases with increasing angle of wall back and increases with increasing soil friction angle, $\phi$.

In Figures 6, 7, and 8, variation of $H_{r}$ with the angle of backfill slope, $\beta$, with $\delta=2 / 3 \phi$ is shown for $\theta=65^{\circ}, 70^{\circ}$, and $75^{\circ}$, respectively. It is seen that $H_{r}$, increases with increasing $\beta$, with higher values for higher soil friction angle, $\phi$.

In Figure 9, variation of $H_{r}$ with the angle of wall friction, $\delta$, is shown for $\beta=16^{\circ}$ and $\phi=40^{\circ}$. It is seen that $H_{r}$ increases with $\delta$, with higher values for higher $\beta$.

In Figure 10 is shown the variation of $H_{r}$ for a vertical wall $\left(\theta=90^{\circ}\right)$ and $\delta=2 / 3 \phi$. It is again seen that $H_{r}$ increases with increase of $\beta$.

In Figure 11, variation of $H_{r}$ with angle of soil friction, $\phi$, is shown for a retaining wall with angle of wall back, $\theta=$ $90^{\circ}$, backfill slope, $\beta=0^{\circ}$, and angle of wall friction, $\delta=0^{\circ}$. It is interesting to note that $H_{r}$ is a constant value of 0.5 for all values of angle of soil friction, $\phi$. Hence, the point of application of active thrust acts at the mid-height of a smooth vertical retaining wall with horizontal backfill. 
TABLe 2: Comparison of $K_{\mathrm{aq}}$ with the results for the angle of wall back of $\theta=80^{\circ}$.

\begin{tabular}{|c|c|c|c|c|c|c|}
\hline \multirow{2}{*}{$\begin{array}{l}\text { Soil friction angle, } \\
\phi \text { (degrees) }\end{array}$} & \multirow{2}{*}{$\begin{array}{c}\text { Angle of backfill } \\
\text { slope, } \beta \text { (degrees) }\end{array}$} & \multirow{2}{*}{$\begin{array}{c}\text { Angle of wall friction, } \delta \\
\text { (degrees) }\end{array}$} & \multirow{2}{*}{$P_{a}(\mathrm{KN} / \mathrm{m})$} & \multicolumn{2}{|c|}{$K_{\mathrm{aq}}$} & \multirow{2}{*}{$\%$ difference } \\
\hline & & & & Present study & $\begin{array}{l}\text { Soubra and } \\
\text { Macuh [21] }\end{array}$ & \\
\hline 40 & 16 & 26.667 & 0.4758 & 0.336 & 0.331 & 1.51 \\
\hline 40 & 24 & 26.667 & 0.561 & 0.396 & 0.382 & 3.66 \\
\hline 40 & 32 & 26.667 & 0.723 & 0.511 & 0.475 & 7.57 \\
\hline 35 & 14 & 23.333 & 0.549 & 0.388 & 0.383 & 1.35 \\
\hline 35 & 21 & 23.333 & 0.638 & 0.451 & 0.439 & 2.73 \\
\hline 35 & 28 & 23.333 & 0.8 & 0.565 & 0.538 & 5.00 \\
\hline 30 & 12 & 20 & 0.631 & 0.446 & 0.44 & 1.36 \\
\hline 30 & 18 & 20 & 0.721 & 0.509 & 0.499 & 2.00 \\
\hline 30 & 24 & 20 & 0.88 & 0.622 & 0.602 & 3.32 \\
\hline 25 & 10 & 16.667 & 0.724 & 0.512 & 0.504 & 1.58 \\
\hline 25 & 15 & 16.667 & 0.813 & 0.574 & 0.566 & 1.41 \\
\hline 25 & 20 & 16.667 & 0.964 & 0.681 & 0.668 & 1.90 \\
\hline
\end{tabular}

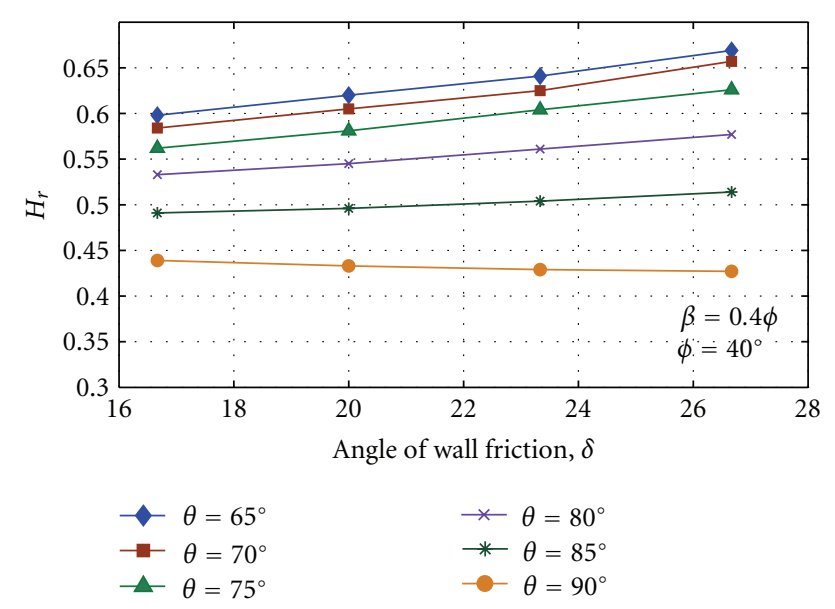

FIGURE 9: Variation of $H_{r}$ with angle of wall friction, $\delta$, for $\phi=40^{\circ}$.

The other aim of the proposed analysis is to compute the values of the active earth pressure coefficient, $K_{\mathrm{aq}}$, for the various combinations of parameters considered in the analysis and compare the results with the available solution reported by Soubra and Macuh [21]. The results are presented through figures. In Figures 12, 13, and 14, the variation of active earth pressure coefficient, $K_{\mathrm{aq}}$ with angle of soil friction, $\phi$ is shown for $\beta=0.4 \phi, 0.6 \phi$, and $0.8 \phi$, respectively, for various values of angle of wall back, $\theta$ and $\delta=2 / 3 \phi$. It is seen that $K_{\mathrm{aq}}$ values decrease with increasing angle of soil friction, $\phi$. It is further seen that the values show an increasing trend with decreasing values of angle of wall back, $\theta$.

In Figure 15 and Table 2 is shown the comparison of active earth pressure coefficients obtained from the proposed method and the method proposed by Soubra and Macuh [21]. The $K_{\mathrm{aq}}$ values obtained from the proposed method are higher with the maximum difference of $7.57 \%$ for the angle of wall back of $\theta=80^{\circ}, \phi \leq 40^{\circ}$, and $\delta=2 / 3 \phi$ as shown in Table 2 . For lower values of soil friction angle, $\phi$, and angle of backfill slope, $\beta$, the difference between the two results is

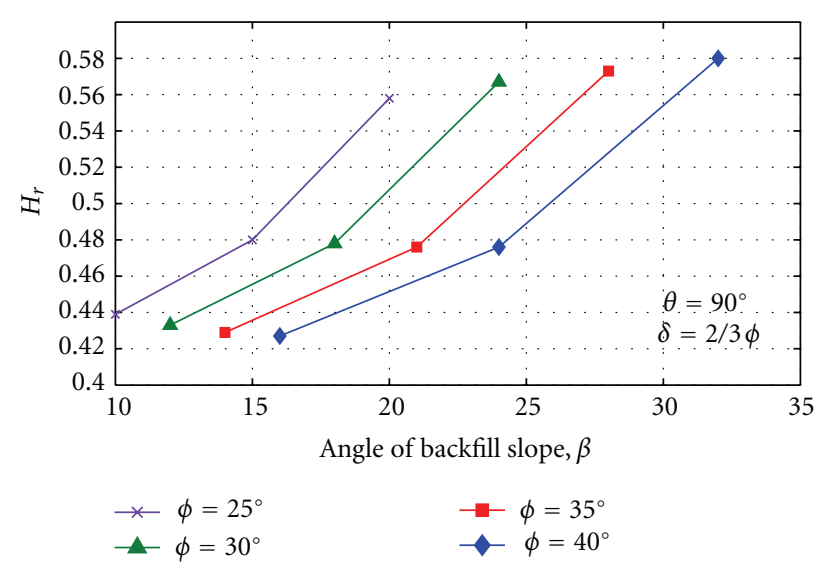

Figure 10: Variation of $H_{r}$ with angle of backfill slope, $\beta$, for $\theta=$ $90^{\circ}$.

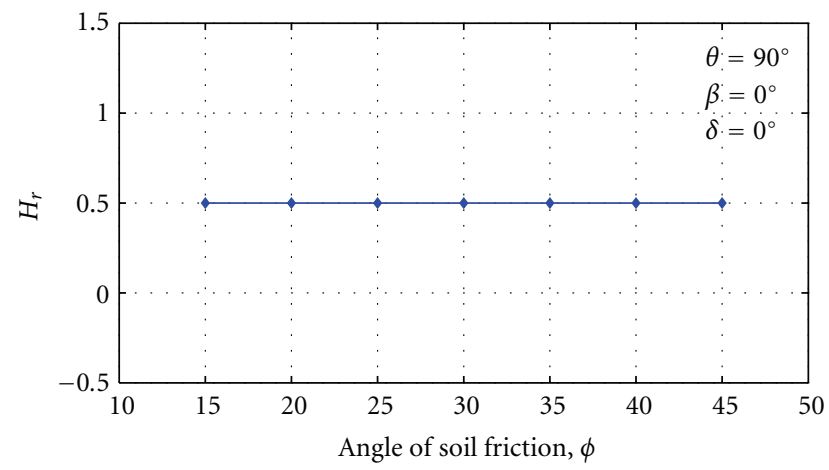

FIGURE 11: Variation of $H_{r}$ with angle of soil friction, $\phi$.

less, showing an increasing trend with increasing angle of soil friction, $\phi$, and backfill slope, $\beta$.

\section{Conclusions}

The complete solution to a retaining wall problem is obtained only when the point of application of active thrust is 


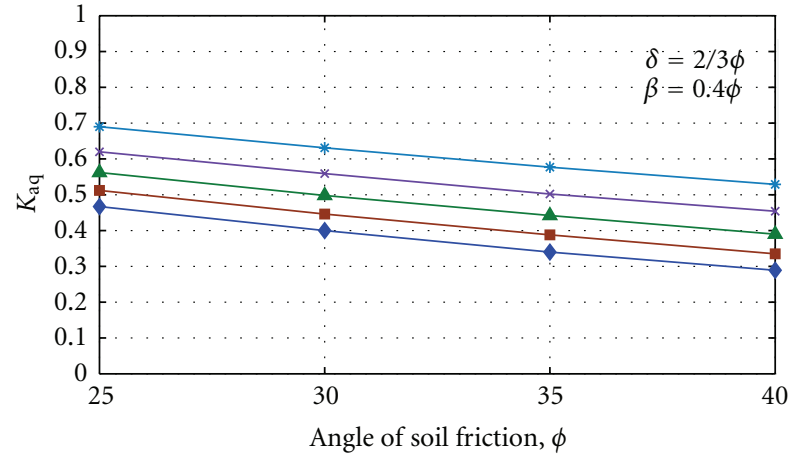

$$
\begin{aligned}
& \multimap \theta=85^{\circ} \quad * \theta=70^{\circ} \\
& \rightarrow \theta=80^{\circ} \quad \rightarrow \theta=65^{\circ} \\
& -\theta=75^{\circ}
\end{aligned}
$$

FIgURE 12: Variation of $K_{\mathrm{aq}}$ with angle of soil friction, $\phi$, for $\beta=$ $0.4 \phi$.

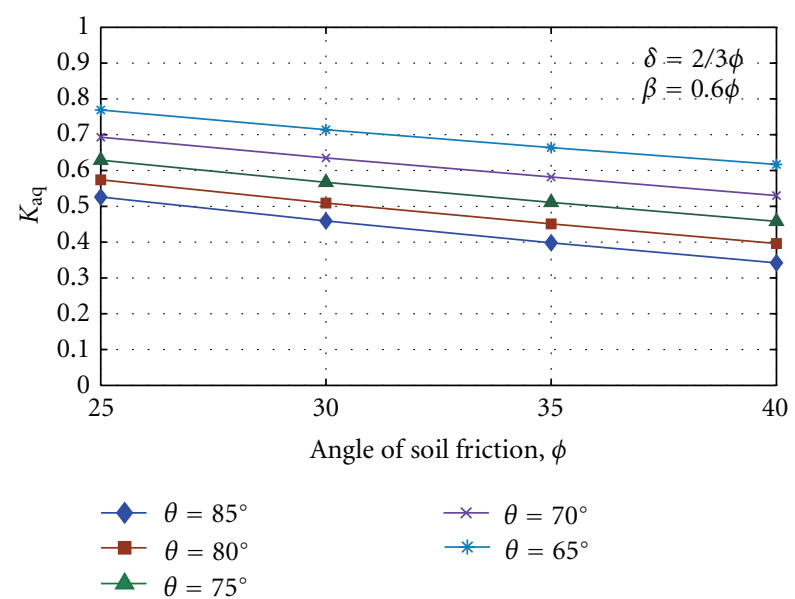

Figure 13: Variation of $K_{\mathrm{aq}}$ with angle of soil friction, $\phi$, for $\beta=$ $0.6 \phi$.

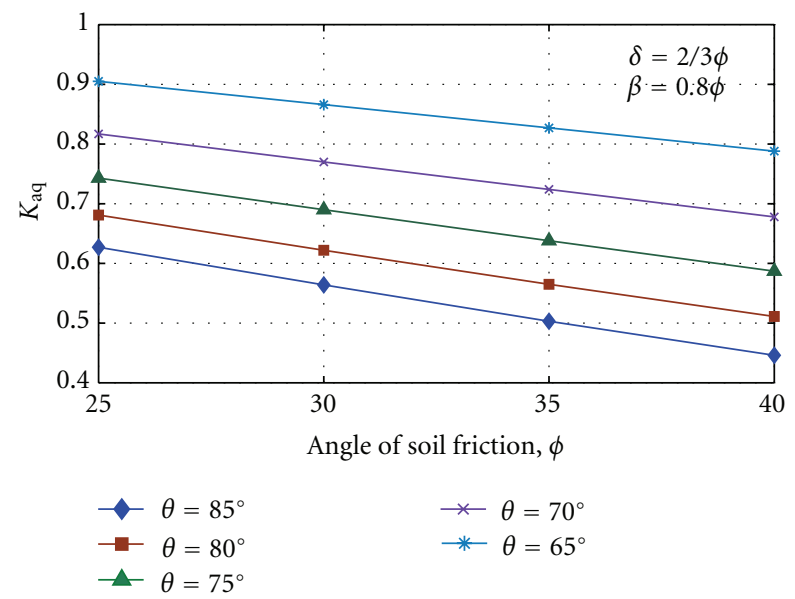

FIgURE 14: Variation of $K_{\mathrm{aq}}$ with angle of soil friction, $\phi$, for $\beta=$ $0.8 \phi$.

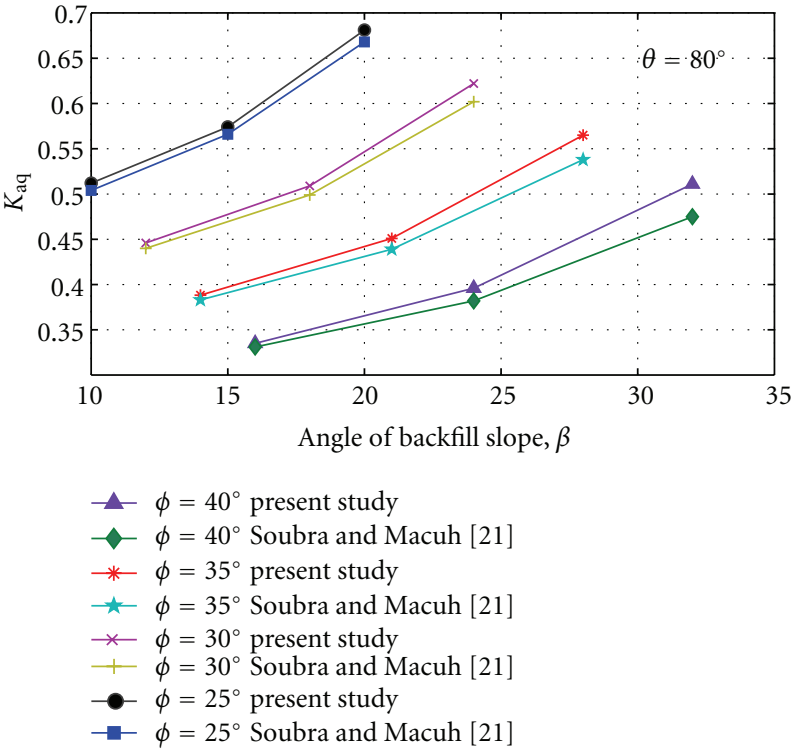

Figure 15: Comparison of variation of $K_{\mathrm{aq}}$ with angle of backfill slope, $\beta$, evaluated in present study with filed results.

known. Kötter's [22] equation lends itself as a powerful tool in the proposed analysis to determine the reactive pressure distribution on the failure plane. The moment equilibrium condition is used effectively to compute the point of application of the active thrust. From the proposed analysis it is seen that the point of application of the active thrust depends upon a number of factors such as angle of soil friction, $\phi$, angle of wall friction, $\delta$, angle of wall back, $\theta$, and inclination of backfill, $\beta$. It shows a wide variation in the range, 0.427 to 0.814 . Only for the case of a smooth vertical wall retaining horizontal backfill, the point of application of the active thrust is at the wall mid-height. The present approach is easy to adapt for retaining walls and the results obtained based on this analysis are in fairly good agreement with other results.

\section{References}

[1] C. A. Coulomb, "Essaisurune application des règles des maximis et minimis à quelquesproblèmes de statiquerelatifs à l'architecture," Mémoires de Mathématiques et de Physique Présentés à l'Académie Royale des Sciences par Divers Savants, vol. 7, pp. 343-382, 1776.

[2] W. J. M. Rankine, "On the stability of loose earth," Philosophical Transactions of the Royal Society, vol. 147, 1857.

[3] K. Terzaghi, Theoretical Soil Mechanics, John Wiley \& Sons, New York, NY, USA, 1943.

[4] J. B. Hansen, Earth Pressure Calculation, Danish Geotechnical Press, Copenhagen, Denmark, 1953.

[5] V. V. Sokolovski, Statics of Soil Media, Butterworth, London, UK, 1960.

[6] Z. V. Tsagareli, "Experimental investigation of the pressure of a loose medium on retaining walls with a vertical back face and horizontal backfill surface," Soil Mechanics and Foundation Engineering, vol. 2, no. 4, pp. 197-200, 1967. 
[7] M. Matsuo, S. Kenmochi, and H. Yagi, "Experimental study on earth pressure of retaining wall by field tests," Soils and Foundations, vol. 18, no. 3, pp. 27-41, 1978.

[8] K. Habibagahi and A. Ghahramani, "Zero extension line theory of earth pressure," Journal of the Geotechnical Engineering Division, vol. 105, no. 14702, pp. 881-896, 1979.

[9] Y. S. Fang and I. Ishibashi, "Static earth pressures with various wall movements," Journal of Geotechnical Engineering, vol. 112, no. 3, pp. 317-333, 1986.

[10] D. M. Potts and A. B. Fourie, "A numerical study of the effects of wall deformation on earth pressures," International Journal for Numerical \& Analytical Methods in Geomechanics, vol. 10, no. 4, pp. 383-405, 1986.

[11] E. Motta, "Generalized Coulomb active earth pressure for a distanced surcharge," Journal of Geotechnical Engineering, vol. 120, no. 6, pp. 1072-1079, 1994.

[12] H. Hazarika and H. Matsuzawa, "Wall displacement modes dependent active earth pressure analyses using smeared shear band method with two bands," Computers and Geotechnics, vol. 19, no. 3, pp. 193-219, 1996.

[13] V. R. Greco, "Active earth thrust by backfills subject to a line surchange," Canadian Geotechnical Journal, vol. 42, no. 5, pp. 1255-1263, 2005.

[14] Y. M. Cheng, Y. Y. Hu, and W. B. Wei, "General axisymmetric active earth pressure by method of characteristics-theory and numerical formulation," International Journal of Geomechanics, vol. 7, no. 1, pp. 1-15, 2007.

[15] A. I. Caquot and J. Kerisel, Tables for the Calculation of Passive Pressure, Active Pressure, and Bearing Capacity of Foundations, Gauthier-Villars, Paris, France, 1948.

[16] N. Janbu, "Earth pressure and bearing capacity calculations by generalized procedure of slices," in Proceedings of the 4th International Conference on Soil Mechanics and Foundation Engineering, vol. 2, pp. 207-212, London, UK, 1957.

[17] H. Rahardjo and D. G. Fredlund, "General limit equilibrium method for lateral earth force," Canadian Geotechnical Journal, vol. 21, no. 1, pp. 166-175, 1984.

[18] J. Kerisel and E. Absi, Active and Passive Earth Pressure Tables, Balkema, Rotterdam, The Netherlands, 1990.

[19] C. S. Chang and S. J. Chao, "Discrete element analysis for active and passive pressure distribution on retaining wall," Computers and Geotechnics, vol. 16, no. 4, pp. 291-310, 1994.

[20] R. Lancellotta, "Analytical solution of passive earth pressure," Geotechnique, vol. 52, no. 8, pp. 617-619, 2002.

[21] A. H. Soubra and B. Macuh, "Active and passive earth pressure coefficients by a kinematical approach," Proceedings of the Institution of Civil Engineers, vol. 155, no. 2, pp. 119-131, 2002.

[22] F. Kötter, Die Bestimmung des Drucks an gekrümmten Gleitflächen, eine Aufgabe aus der Lehre vom Erddruck, Sitzungsberichte der Akademie der Wissenschaften, Berlin, Germany, 1903.

[23] D. M. Dewaikar and S. A. Halkude, "Seismic passive/active thrust on retaining wall-point of application," Soils and Foundations, vol. 42, no. 1, pp. 9-15, 2002.

[24] G. S. Kame, D. M. Dewaikar, and D. Choudhury, "Active thrust on a vertical retaining wall with cohesionless backfill," Electronic Journal of Geotechnical Engineering, vol. 15, pp. 1848-1863, 2010.

[25] D. M. Dewaikar, S. R. Pandey, and J. Dixit, "Active earth pressure on an inclined wall with horizontal cohesionless backfill due to surcharge effect," Electronic Journal of Geotechnical Engineering, vol. 17, pp. 811-824, 2012. 

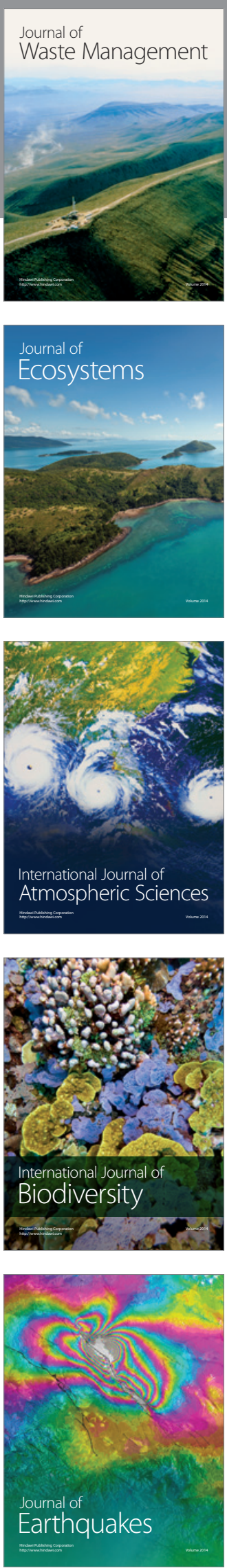
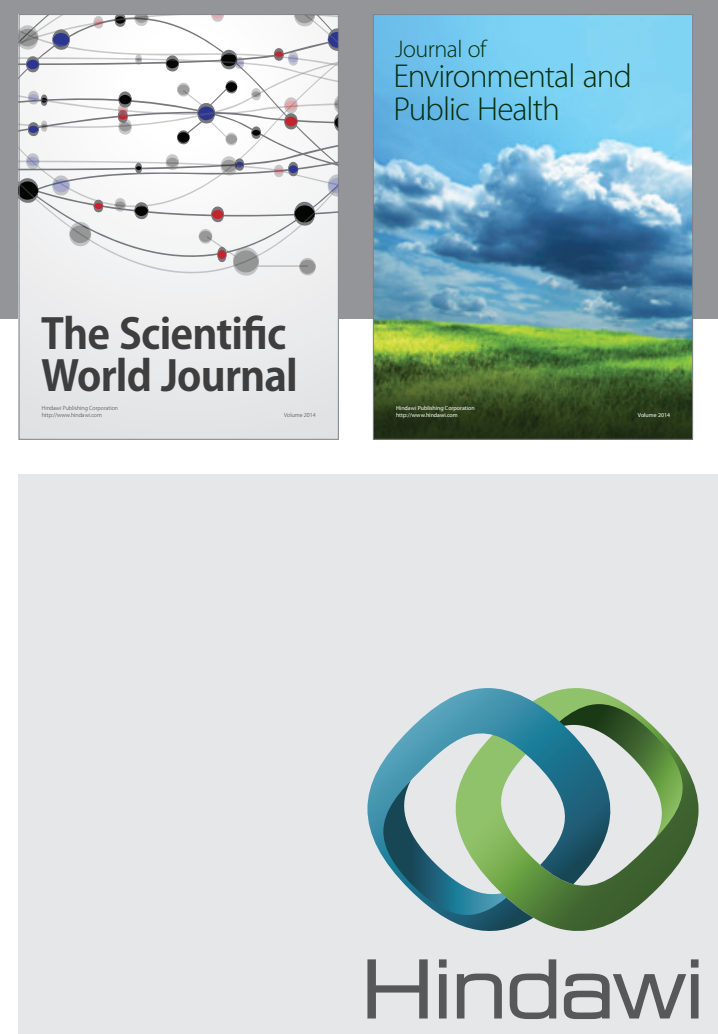

Submit your manuscripts at

http://www.hindawi.com
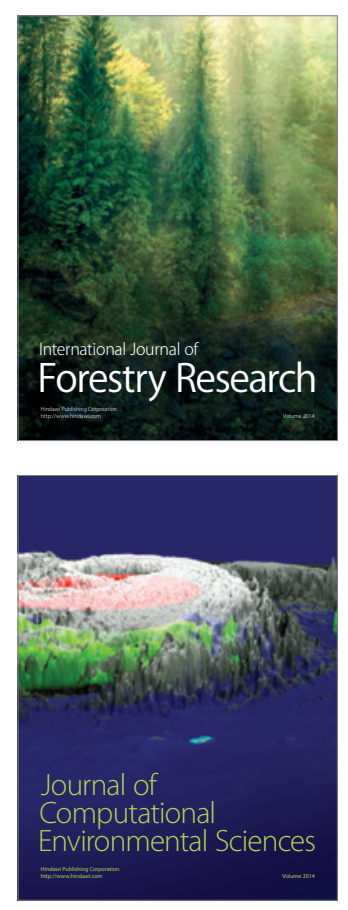
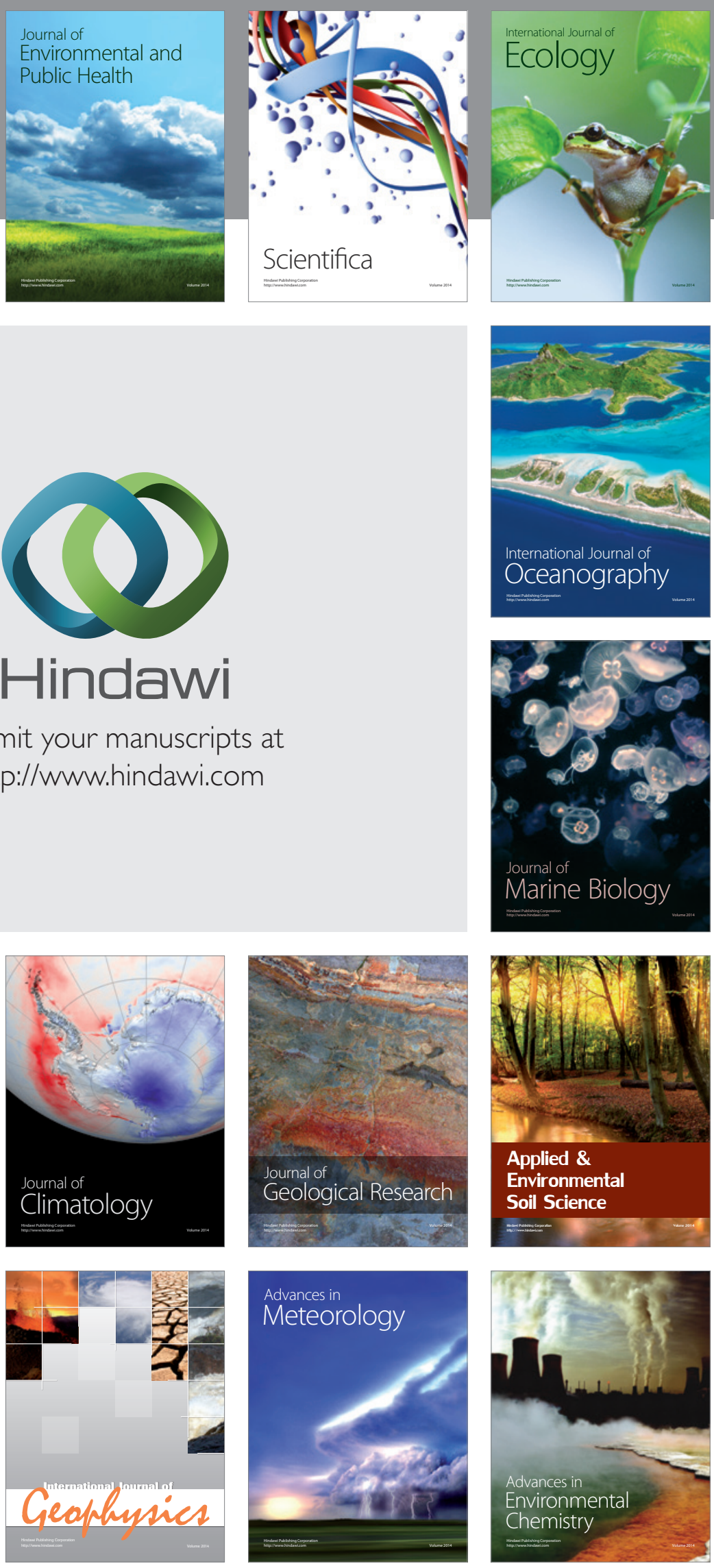